\title{
Systemic Risk in China's Financial Industry Due to the COVID-19 Pandemic
}

\author{
Cheng Lan', Ziyi Huang' ${ }^{1}$, Wenli Huang ${ }^{1}$ \\ ${ }^{1}$ China Academy of Financial Research, Zhejiang University of Finance \& Economics, China \\ Keywords: systemic financial risk, dynamic covar, covid-19 \\ 10.46557/001c.18070
}

\section{Asian Economics Letters}

In this paper, the dynamic CoVaR method is used to measure changes in systemic risk in the financial industry during the COVID-19 pandemic. We find that, first, after the outbreak of the COVID-19 pandemic, the systemic risk of the financial industry increased significantly. Second, the impact of the COVID-19 pandemic on the systemic risk of the securities industry was greater than that of the banking and insurance industries.

\section{Introduction}

In this paper, we (a) test the impact of COVID-19 on the systemic risks of China's financial industry, and (b) evaluate which industry experienced the largest fluctuations in systemic risks. Investigating both (a) and (b) are important because China's financial system is not yet perfect, and the ability to prevent and resolve financial systemic risks caused by market emergencies needs to be improved (Bai \& Shi, 2014). The outbreak of the COVID-19 pandemic has had a serious economic impact on China's economy. ${ }^{1}$ The pandemic has also impacted the financial industry. In response, banks reduced credit demand and intermediary business, and overdue loans have increased. Moreover, sales of the insurance industry have been severely affected by the pandemic, and sales of traditional insurance types have fallen sharply. The securities industry has been affected by market sentiment, and trading volume, investment and financing activities have fluctuated greatly; see, for instance, Zuo (2020), Duan (2020), Ni et al. (2020).

According to Zuo (2020), the banking, insurance, and securities industries have become closely linked, and the comprehensive operation of various industries has also intensified the transmission of risks within the financial industry. Cross-contagion and superimposed resonance of risks may further induce financial systemic risks.

We use the CoVaR-the value at risk (VaR) of the financial system conditional on institutions being under distress. This method was proposed by Adrian \& Brunnermeier (2016) and provides a way to measure the loss of investment portfolios of other financial markets or financial institutions under crisis or high-risk conditions. Adrian \& Brunnermeier (2016) constructed CoVaR, Exposure-CoVaR, Network-CoVaR, and Forward-CoVaR based on the CoVaR method. These are a series of systemic risk measurement indicators based on risk spillover and tail dependence among financial institutions. Many studies (Bai \& Shi, 2014) adopt new methods, such as the CoVaR and the Marginal Expected Shortfall-System Risk (MES-SRISK) to mea- sure the systemic risk level of China's financial institutions, assess the risk contribution of individual institutions, and monitor the dynamic changes of China's systemic financial risks. Among these methods, the CoVaR method combined with the traditional VaR can more accurately capture the impact of a single financial institution's risk on systemic risk, and it can also accurately measure the risk spillover effect in the financial network. Our contribution to the literature is through analyzing the effects of COVID-19 on systemic risk of the financial industry in China. This has not been done previously and nothing is understood on COVID-19 and the financial industry effects.

The remainder of this paper proceeds as follows. Section II provides the research model and data. Section III presents the empirical results. Section IV concludes this work.

\section{Methodology and Data \\ A. Calculation of systemic financial risk}

The paper first draws on the systemic risk indicator $\Delta \mathrm{CoVaR} R_{q}^{\text {system } \mid}{ }^{i}$ proposed by Adrian \& Brunnermeier (2016) to calculate the systemic risk of financial institution $i$, where $\Delta \mathrm{CoVaR} \mathrm{R}_{q}^{\text {system } i} i$ indicates the contribution of financial institution $i$ to the systemic risk of the financial system.

$$
\operatorname{Pr}\left(X^{j} \leq \operatorname{CoV} a R_{q}^{j \mid i} \mid X^{i}=V a R_{q}^{i}\right)=q
$$

$V a R_{q}^{i}$ is the VaR of institution $i$ under the confidence level of q. $\operatorname{Pr}\left(X^{i} \leq V a R_{q}^{i}\right)=q$ where $X^{i}$ represents the rate of return of institution i. $\mathrm{CoVaR} R_{q}^{j l i}$ represents the VaR of institution $j$ when institution $i$ is in crisis and the loss is $V a R_{q}^{i}$. The contribution of a single financial institution $i$ to the systemic risk of the financial institution $j$ (or system) can be obtained as:

$$
\Delta \mathrm{CoVaR}_{q}^{j \mid i}=\mathrm{CoVaR} R_{q}^{j \mid X^{i}=\operatorname{VaR}_{q}^{i}}-\mathrm{CoVaR} R_{q}^{j \mid X^{i}=\mathrm{Median}^{i}}
$$

According to definitions, contributions from individual financial institution $i$ to the systemic risks of the financial system is derived:

\footnotetext{
a Corresponding author: China Academy of Financial Research, Zhejiang University of Finance \& Economics. No.18, Xueyuan Street, Xiasha Higher Education Zone, Hangzhou Zhejiang 310018, P.R. China E-mail: poppy.huang3282@foxmail.com

Helpful comments and suggestions from a referee of this journal is acknowledged.

1 See Iyke (2020).
} 


$$
\begin{gathered}
\Delta \operatorname{CoVaR} R_{q}^{\text {system } \mid} i \\
=\operatorname{CoVaR} R_{q}^{\text {system } \mid X^{i}=\operatorname{VaR}_{q}^{i}}-\operatorname{CoVaR}_{q}^{\text {system } \mid X^{i}=\operatorname{VaR} R^{\text {Mediani }}}
\end{gathered}
$$

Mediani uses $V a R_{50 \%}^{i}$, which represents the VaR of the financial institution $i$ at the level of the $50 \%$ confidence interval. It represents the financial institution in a normal state. In this paper, the value of $q$ is $95 \%$, which is the $95 \%$ confidence interval.

Since financial data in reality is often not distributed normally but distributed with "high peak and fat tail", in order to more accurately capture the relationship between different parts of the overall distribution, a quantile regression is introduced on this basis to form dynamic CoVaR. Quantile regression is a regression based on the different quantiles of variables and includes the state variable, $M_{t}$, to calculate the time series of the contribution of a single financial institution to the systemic risk.

Firstly, quantile regression is used to calculate the dynamic VaR of the financial institution $i$ at the $95 \%$ and $50 \%$ confidence levels. The quantile regression equation form is:

$$
X_{t}^{i}=\alpha^{i}+\gamma^{i} M_{t}+\varepsilon_{t}^{i}
$$

$X_{t}^{i}$ represents the rate of return of institution $i$ at time $t$, and $\boldsymbol{M}_{t}$ is a state variable, which specifically covers three categories, namely liquidity risk, credit risk, stock market risk; see Table 1 for details.

Secondly, quantile regression is used to calculate the VaR of the financial system under the 95\% confidence level when the financial institution $i$ is under pressure and normal. The regression equation is as follows:

$$
X_{t}^{\text {system }}=\alpha^{\text {system } \mid i}+\beta^{\text {system } \mid i} X_{t}^{i}+\gamma^{\text {system } \mid i} M_{t}+\varepsilon_{t}^{\text {system } \mid i} \text { (5) }
$$

$X_{t}^{i}$ and $M_{t}$ have the same meanings as in Equation (4), $X_{t}^{\text {system }}$ is the rate of return of the financial system at time $t$, expressed as the logarithmic growth rate of each financial industry index. What needs to be pointed out is that when calculating systemic risks in different financial industries, the logarithmic growth rates of different financial indexes should be used; see Table 1 for details. get:

By regressing, we obtain the predicted value, so we can

$$
\begin{aligned}
& \operatorname{VaR}_{t}^{i}(q)=\hat{\alpha}_{q}^{i}+\hat{\gamma}_{q}^{i} M_{t} \\
& \operatorname{CoVaR}_{t}^{i}(q)=\hat{\alpha}_{q}^{\text {system } \mid i}+\hat{\beta}^{\text {system } \mid i} \operatorname{VaR}_{t}^{i}(q)+\hat{\gamma}_{q}^{\text {system } \mid i} M_{t}
\end{aligned}
$$

Then the contribution of a single financial institution to systemic risk $\triangle \mathrm{CoVaR} R_{q}^{\text {system } \mid} i$ can be expressed as:

$$
\begin{aligned}
& \Delta \operatorname{CoVaR}_{t}^{\text {systemli }}(q)=\operatorname{CoVaR} R_{t}^{i}(q)-\operatorname{CoVaR}{ }_{t}^{i}(50 \%) \\
& =\widehat{\beta}^{\text {system } \mid i}\left(\operatorname{VaR}_{t}^{i}(q)-\operatorname{VaR}_{t}^{i}(50 \%)\right)
\end{aligned}
$$

After obtaining the contribution of each institution in the three industries to the systemic risks of financial institutions, it is necessary to finally calculate the systemic financial risks of the three industries over time, as:

$$
\Delta \mathrm{CoVaR} \mathrm{R}_{t}^{\text {system }}=\sum \frac{V_{i, t}}{V_{\text {system }, t}} \Delta \mathrm{CoVaR} R_{t}^{\text {system } \mid i}
$$

Where $\Delta \mathrm{CoVaR} R_{t}^{\text {system }}$ represents the systemic financial risk of a financial industry at time $t ; \Delta \mathrm{CoVaR}{ }_{t}^{\text {system } \mid i}$ represents the contribution value of financial institution $i$ to the systemic risk of the financial industry at time $t ; V_{i, t}$ represents the market value of institution $i$ at time $t$, represented by the market value of equity on that day; $V_{\text {system, } t}$ represents the total market value of the industry in which institution $i$ belongs at time $t$, and the ratio of the two is the weight of the industry in which institution $i$ belongs.

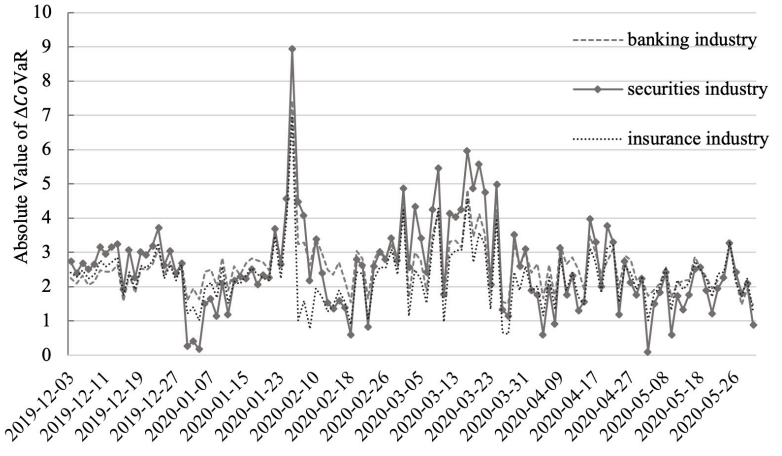

Figure 1: Trends of systemic risk in various financial industries

The figure shows the trends of systemic risk in various financial industries between December 2019 to May 2020. Since $\Delta \mathrm{CoVaR} R_{t}^{\text {system }}$ has positive and negative values, for simplicity, Figure 1 takes its absolute value to represent risk.

\section{B. Data Selection}

This paper selects non-special-treatment companies in various industries that were listed as A shares before December 2019, including a total of 30 listed banking companies, 46 listed securities companies, and seven insurance companies (according to the new China Securities Regulatory Commission industry classification). The sample interval is from December 2, 2019 to May 31, 2020. The basic variables and related descriptive statistics used to calculate systemic risks (explained variables) in various financial industries are given in Table 1.

\section{Results and Analysis}

Section III contains two parts of analysis. The first part analyzes the overall situation of systemic risks in the financial industry before and after the outbreak of the COVID-19 pandemic based on systemic risk data. The second part takes a comparative analysis of the systemic risk trends of the banking, securities, and insurance industries.

\section{A. Overall analysis of systemic risks before and after the COVID-19 pandemic}

As Figure 1 shows, the larger the absolute value, the greater the institutional risk. It can be concluded from Figure 1 that the occurrence of COVID-19 has increased the volatility of systemic risks in the financial industry. Specifically, in December 2019, before the outbreak of COVID-19, the fluctuation in systemic risk was relatively stable. In February with the outbreak of COVID-19, the degree of fluctuation of systemic risk increased greatly. Since important news about COVID-19 was released during the holiday period (the Spring Festival), the information backlog caused a linear increase in systemic risks from the beginning of February. With the pandemic persisting post-February, the volatility of systemic risks was significantly higher than in December. Due to the uncertainty brought about by COVID-19, it has not only increased systemic financial risks, but also increased the volatility of systemic risks in the financial system. 
Table 1: Data description and descriptive statistics

Panel A: Data description

\begin{tabular}{|c|c|c|c|c|}
\hline \multicolumn{5}{|c|}{ Panel A: Data description } \\
\hline Variable & \multicolumn{4}{|l|}{ Description } \\
\hline Syl_i & \multicolumn{4}{|c|}{$\begin{array}{l}\text { CSI } 300 \text { industry } i \text { index return rate, represents the rate of return of institution } i, i=\text { bank, sec, ins, where bank } \\
\text { represents banking, sec represents securities industry, ins represents insurance industry. }\end{array}$} \\
\hline$V_{i, t}$ & \multicolumn{4}{|c|}{ The return rate of the $i$-th listed company in the industry at time $t$. } \\
\hline M1 & \multicolumn{4}{|c|}{ CSI 300 Index Growth Rate, logarithmic growth rate. } \\
\hline M2 & \multicolumn{4}{|c|}{ CSI 300 Index Volatility, reflects the fluctuation of the stock market, obtained using a GARCH(1,1) model. } \\
\hline M3 & \multicolumn{4}{|c|}{ Changes in the yield to maturity of 3-month Treasury bonds, reflects changes in spreads. } \\
\hline M4 & \multicolumn{4}{|c|}{$\begin{array}{l}\text { Term spread, Shanghai Clearing House's 1-year treasury bond yield to maturity minus the 3-month treasury bond } \\
\text { yield, reflecting market liquidity. }\end{array}$} \\
\hline M5 & \multicolumn{4}{|c|}{$\begin{array}{l}\text { Credit spread, the one-year maturity certificate AAA corporate bond yield minus the one-year maturity treasury } \\
\text { bond yield, reflecting the credit risk of the market. }\end{array}$} \\
\hline \multicolumn{5}{|c|}{ Panel B: Descriptive statistics } \\
\hline Variable & Mean & SD & Min & Max \\
\hline Syl_bank & -0.0865 & 1.2648 & -6.7125 & 2.6202 \\
\hline Syl_sec & -0.0071 & 2.2064 & 10.5277 & 6.0372 \\
\hline Syl_ins & -0.1411 & 1.6403 & -7.6517 & 3.4802 \\
\hline CoVaR_bank & 2.6131 & 0.8104 & 1.4681 & 7.4278 \\
\hline CoVaR_sec & 2.5715 & 1.3187 & 0.0911 & 8.9346 \\
\hline CoVaR_ins & 2.2747 & 0.8813 & 0.6130 & 6.9841 \\
\hline M1 & 1.4257 & 0.5505 & 0.9319 & 4.0852 \\
\hline M2 & 0.0068 & 1.5172 & -8.2088 & 3.2368 \\
\hline M3 & -0.2867 & 4.9129 & 18.5345 & 18.461 \\
\hline M4 & 0.2414 & 0.0850 & 0.0752 & 0.4241 \\
\hline M5 & 0.7130 & 0.1043 & 0.3903 & 0.9721 \\
\hline
\end{tabular}

Note: In Panel A of this table, we provide detailed description of the data used in this study. Panel B reports descriptive statistics (mean, maximum, minimum, standard deviation (SD)

\section{B. Comparative analysis of systemic risk trends in three industries}

As Figure 1 indicates, we can see that compared with banking and insurance industries, securities industry has greater systemic risks and higher volatility. The systemic changes in the banking and the insurance industries are similar, and the absolute value and the degree of volatility are relatively small compared to the securities industry. This shows that the pandemic has had a greater impact on securities in the financial industry. The securities industry has the highest contribution to systemic financial risks. There may be several reasons for this.

According to Wang et al. (2020), in China, the insurance industry has strong connections with the banking industry. In terms of business, the insurance industry cooperates with the banking sector to complete part of insurance sales. In terms of policies, the China Banking Regulatory Commission and the China Insurance Regulatory Commission have also merged into the China Banking Regulatory Commission. The business structure of the insurance industry is relatively simple, which leads to weak externalities of the insurance industry. Therefore, the systemic risk of this industry is relatively small compared to the banking and securities industries.

Compared with the banking and insurance industries, the securities industry is involved in a large number of derivative financial product transactions, which is risky. For example, the liquidation and settlement risks of derivative product transactions have greatly increased. At the same time, excessive speculation and high-risk investment speculation in the securities market has increased risks in the securities industry.

\section{Conclusion}

In this paper, we start on exploring systemic risks on the financial industry motivated by the broader implications of the COVID-19 pandemic. Selecting daily data for 30 listed banking companies, 46 listed securities companies and seven insurance companies between December 2019 to May 2020, we apply the dynamic CoVaR method to measure changes in systemic risk in the financial industry during the COVID-19 pandemic. The results show that during the COVID-19 pandemic, the systemic financial risks of various financial industries increased significantly, and the degree of volatility also increased. We find that the impact of the COVID-19 pandemic on the systemic risks of the securities industry is greater than that of the banking and insurance industries. Therefore, policymakers should rationally guide the direction of capital investment in the securities industry. 


\section{Acknowledgements}

Helpful comments and suggestions from a referee of this journal is acknowledged.
Submitted: October 31, 2020 AEDT, Accepted: November 20,

2020 AEDT

This is an open-access article distributed under the terms of the Creative Commons Attribution 4.0 International License (CCBY-SA-4.0). View this license's legal deed at https://creativecommons.org/licenses/by-sa/4.0 and legal code at https://creativecommons.org/licenses/by-sa/4.0/legalcode for more information. 


\section{REFERENCES}

Adrian, T., \& Brunnermeier, M. K. (2016). CoVaR. American Economic Review, 106(7), 1705-1741. http s://doi.org/10.1257/aer.20120555

Bai, X., \& Shi, D. (2014). Systemic Risk Measurement of China's Financial System. Studies of International Finance, 000(006), 75-85.

Duan, Y. (2020). The Impact of the COVID-19 Pandemic on China's Stock Market: An Empirical Analysis Based on the Pharmaceutical Industry. Chinese Commerce, (18), 28-30.

Iyke, B. N. (2020). Economic Policy Uncertainty in Times of COVID-19 Pandemic. Asian Economics Letters, 1(2). https://doi.org/10.46557/001c.17665
Ni, W., Yue, R., \& Wan, R. (2020). Research on Improving Emergency Financial Service Mechanism of Commercial Banks in Post-pandemic Era. Business and Economy, (09), 184-186.

Wang, Y., Feng, Y., \& Zhou, Y. (2020). Does the Insurance Industry Play a "Media” Role in the Path of Financial Systemic Risk Transmission? Based on the Empirical Analysis of the Tail Risk Contagion Path of the Financial Market. Chinese Journal of Management Science, 1-12.

Zuo, Z. (2020). Theoretical Analysis of Systemic Financial Risk Contagion under Shock Conditions: Based on the Perspective of the COVID-19 Pandemic. China's Prices, (11), 59-62. 